\section{POST-CRICOID CARCINOMA IN PATIENTS WITH PERNICIOUS ANAEMIA}

BY

ALLAN JACOBS,* M.D.

Department of Pathology, St. Mary's Hospital, London

Post-cricoid carcinoma occurs mainly in women and is often associated with a history of iron-deficiency anaemia. In some cases dysphagia has been present for many years. An association of this type of cancer with pernicious anaemia is not generally recognized. A recent study of 93 cases of post-cricoid carcinoma (Jacobs, 1961a) showed that 29 had suffered from iron-deficiency anaemia and that five were being treated for pernicious anaemia. In two of these five cases the full notes of the original haematological investigations are unobtainable, so that the diagnosis cannot now be fully established. Details of the other cases are reported here and discussed in the light of current views on the aetiology of post-cricoid carcinoma.

\section{Case 1}

A married woman aged 51 was first seen at St. Mary's Hospital in July, 1950. She had not felt well for over a year, and in the last three months had been short of breath after exercise and had noticed some swelling of her ankles. During the year she had also noticed an increasing patchy pigmentation and vitiligo of the arms. There was no relevant history prior to this.

Examination showed a marked degree of pallor ; bloodpressure $120 / 80$. The jugular venous pressure was $5 \mathrm{~cm}$. above the sternal notch, and a systolic bruit was heard in the pulmonary area. There were no other physical signs, but it was noted that the patient was garrulous and somewhat disorientated.

Investigations.-Hb 40\% (Haldane) ; R.B.C. 1,700,000/ c.mm.; C.I. 1.2 ; M.C.D. $8.7 \mu$; M.C.V. 111 cubic ".; W.B.C. $5,000 / \mathrm{c} . \mathrm{mm}$. Red cells showed marked anisocytosis and poikilocytosis. Fractional test meal revealed a histamine-fast achlorhydria. Serum bilirubin $1.5 \mathrm{mg}$./ $100 \mathrm{ml}$. Bone-marrow aspirate showed megaloblastic haemopoiesis.

Treatment was started with injections of " hepolon" liver extract. The reticulocyte count rose to $14 \%$ on the seventh day, and when the patient left hospital on the 29th day of treatment she was much improved; $\mathrm{Hb} 67 \%$ (Haldane), C.I. 1.0, M.C.D. $7.7 \mu$.

The patient remained well until July, 1954, when she complained that swallowing had become difficult in the preceding six months and was rapidly getting worse. Direct questioning revealed that she had, in fact, had slight dysphagia for about 16 years, but had paid no attention to it. An inoperable post-cricoid carcinoma was found and a gastrostomy was performed. The patient died a week later, and at necropsy bilateral bronchopneumonia with multiple lung abscesses was found in addition to a squamous carcinoma in the post-cricoid region.

\section{Case 2}

A married woman aged 69 had been treated by her private doctor with oral iron for 20 years, and for most of that time she had had a sensation of food sticking at the level of the suprasternal notch. This did not worry her unduly, but in December, 1951, she complained of palpitations and dyspncea on exertion and was seen at St. Mary's Hospital. Examination showed her to be a little

*Now in the Department of Haematology, Cardiff Royal Infirmary. pale. She had normal fingernails, but her tongue was smooth. The liver edge was just palpable, and vibration sense was absent from the legs. Blood investigation showed no gross anaemia; $\mathrm{Hb} 80 \%$ (Haldane) ; R.B.C. 3,500,000/ c.mm.; C.I. 1.2 .

The patient continued taking iron and was not seen again until May, 1952, when the following blood values were found: $\mathrm{Hb} 53 \%$ (Haldane); M.C.H.C. $32.5 \%$; M.C.V. 120 cubic $\mu$; M.C.D. $8.5 \mu$. Red cells showed marked anisocytosis and poikilocytosis. The bone-marrow contained numerous megaloblasts. A barium swallow was performed and the report states: "At the level of C 6 there was a shelf-like projection from the anterior wall of the oesophagus with a very slight indentation immediately opposite on the posterior wall. This persisted throughout the examination. but caused no appreciable hold-up." The patient refusil oesophagoscopy, and treatment was started with injection. of vitamin $\mathbf{B}_{12}$ (" cytamen "). Her blood picture returned to normal, and the regular administration of $100 \mu \mathrm{g}$. if vitamin $\mathbf{B}_{12}$ every two weeks was supervised by her doctor. No relapse of her blood condition occurred at any time after this.

In December, 1953, she returned to hospital complaining that her difficulty in swallowing had been a little worse during the past year or so. There was no sign of iron deficiency at this time or of any relapse of her pernicious anaemia. A report on a further barium swallow says: "Localized narrowing at the pharyngo-oesophageal junction. No interference with swallowing. The appearances are probably due to scar formation, but it is not possible to altogether exclude malignancy." It was thought that these changes were essentially the same as those seen in 1952. Oesophagoscopy was again refused. In the following month it became impossible for the patient to swallow solid food, and she finally consented to a full investigation in April, 1959. On oesophagoscopy an annular post-cricoid growth was found with the histological features of a squamous carcinoma. A radical operation was refused, but a gastrostomy was performed. The patient died in June, 1959 , in a grossly wasted condition, and at necropsy carcinomatous metastases were found in the cervical lymph nodes.

\section{Case 3}

A married woman aged 45 was first seen at St. Mary's Hospital in November, 1952, when she had been feeling tired and weak for a few months. She was short of breath on exertion, and also complained of "pins and needles" in her hands and legs.

Examination of her blood showed $\mathrm{Hb} 36 \%$ (Haldane). R.B.C. $1,550,000 /$ c.mm., C.I. 1.1. There was megaloblastic haemopoiesis in the bone-marrow, and gastric analysis revealed a histamine-fast achlorhydria. Treatment with vitamin $\mathbf{B}_{12}$ (cytamen) stimulated a peak reticulocyte response of $27 \%$ on the 15 th day. The patient was given $100 \mu \mathrm{g}$. of vitamin $\mathrm{B}_{12}$ weekly, and remained quite well with a normal blood count until April, 1954, when she complained of $\dot{a}$ peculiar dry sensation in her throat. A barium swallow and indirect laryngoscopy showed a post-cricoid growth, and biopsy proved this to be a squamous carcinoma.

In August, 1954, a pharyngo-laryngectomy and repair was performed successfully by Mr. J. F. Simpson, but in the following month the patient suddenly died, and at a postmortem examination massive pulmonary embolism following venous thrombosis in the legs was found.

\section{Discussion}

The syndrome of chronic dysphagia in women first described by Paterson (1919) and Kelly (1919) is usually associated with iron-deficiency anaemia and gastric achlorhydria (Moersch and Conner, 1926 ; Witts, 1931). It has also been found that patients with this syndrome develop carcinoma in the post-cricoid region with a frequency much greater than in the normal population 
(Simpson, 1939 ; Owen, 1950 ; Flett, 1961, personal communication). Ahlbom (1936) stated that $70 \%$ of his cases of post-cricoid carcinoma had had either "Plummer-Vinson's" syndrome or simple achlorhydric anaemia. It has been assumed that the atrophic changes that occur in the bucco-pharyngeal mucosa of patients with iron-deficiency anaemia are in themselves precancerous (Ahlbom, 1936 ; Welin, 1953 ; Boyd, 1961). Lederman (1956) states that late recurrences in postcricoid carcinoma are more common than would be expected, owing to the premalignant condition of the mucosa resulting from iron deficiency. Most authors emphasize the need for adequate iron therapy in the Paterson-Kelly syndrome.

The association of dysphagia with pernicious anaemia has been reported in the past (Jones and Owen, 1928 ; Croskery, 1928 ; McGibbon, 1935) and I also have seen cases. Waldenström and Kjellberg (1939) examined 64 cases of pernicious anaemia for the presence of postcricoid lesions. Webs were present in two cases, but these were assumed to be due to occult sideropenia. Brown (1946) noted dysphagia in 5 out of 78 cases of pernicious anaemia. Simpson (1939) reported a case of post-cricoid carcinoma in a patient suffering from pernicious anaemia, and Wilkinson (1950) found 11 cases of bucco-pharyngeal carcinoma among 1,820 cases of pernicious anaemia. Jones (1961) noted six cases of " macrocytic" anaemia among 322 cases of post-cricoid carcinoma.

The present cases are all in women and have occurred at the time of life when post-cricoid cancer is usually seen. The duration of overt pernicious anaemia in all these cases was relatively short, varying from two to seven years before the occurrence of carcinoma. Two of the patients, however, had suffered from dysphagia for many years, and one of these had been receiving oral iron therapy from her doctor for 20 years because of "an anaemic tendency." None of the patients showed any haematological manifestation of iron deficiency while attending hospital.

The importance of iron deficiency, as such, in the causation of precancerous and cancerous lesions of the bucco-pharyngeal mucosa is not clear. Studies of the buccal mucosa have shown that although atrophic changes with glycogen depletion are found in cases of iron-deficiency anaemia the same changes occur more often in pernicious anaemia (Jacobs, 1960, 1961b). The epithelia adjacent to post-cricoid carcinomas show no atrophic changes, and the occasional occurrence in them of glycogen depletion is apparently unrelated to a previous history of anaemia (Jacobs, 1961a). Weisberger (1957) studied leucoplakia of the mouth in non-smoking post-menopausal women, and noted, in addition to glycogen depletion of the epithelium, a $43 \%$ incidence of achlorhydria and the frequent observation of macrocytosis in blood films in the absence of anaemia.

It is uncertain whether iron deficiency alone can cause dysphagia. Hypochromic anaemia is commonplace in many tropical countries and yet dysphagia rarely appears to be a symptom. Trowell (1960) and Foy (1961, personal communication) state that they have never seen a case of the Paterson-Kelly syndrome among Africans despite the frequency of severe and chronic iron-deficiency anaemia. Wynder and Fryer (1958) found normal serum iron levels in $68 \%$ of cases of the Paterson-Kelly syndrome in women. Kirchen- berger and Flett (1946) and Jones (1961) indicate that the recurrence of dysphagia in the Paterson-Kelly syndrome is unrelated to the discontinuance of iron therapy, and indeed two of the present patients suffered from chronic dysphagia-one with no sign of iron deficiency and the other while on continuous treatment with iron. Weisberger (1957) doubts whether recurrence of post-cricoid carcinoma can be prevented by iron therapy.

The occurrence of post-cricoid carcinoma in association with achlorhydric iron-deficiency anaemia and also with pernicious anaemia draws attention to the background of gastric atrophy common to both these conditions and also to its well-recognized familial incidence. Evidence of a familial predisposition to this type of cancer would be difficult to obtain owing to its relative rarity, but Simpson (1939) records the interesting history of a woman with pernicious anaemia who later developed a post-cricoid cancer. Her sister had died from the same type of growth some years before and a third sister suffered from anaemia with dysphagia but refused investigation. Wynder and Fryer (1958) report the case of a man aged 37 with carcinoma of the lower hypopharynx who had had dysphagia for as long as he could remember. One of his sisters had suffered from anaemia with dysphagia and another sister was also anaemic. Post-cricoid carcinoma, like pernicious anaemia and the Paterson-Kelly syndrome, appears to be confined largely to the North European races, and it may be that nutritional or other factors operating on constitutionally susceptible individuals initiate the pharyngeal abnormality. The role of iron deficiency is uncertain. In the present cases it did not appear to play any part in the aetiology, and in other cases its direct causal relationship has yet to be finally established.

\section{Summary}

Three cases of post-cricoid carcinoma occurring in patients with pernicious anaemia are reported. It seems possible that iron deficiency alone does not predispose either to benign mucosal changes in the mouth and pharynx or to the development of carcinoma.

I thank Mr. J. F. Simpsen and Dr. C. A. Young for permission to quote clinical details of these cases.

\section{REFERENCES}

Ahlbom, H. E. (1936). Brit. med. J., 2, 331

Boyd, W. (1961). Textbook of Pathology, 7th ed. Kimpton, London.

Brown, A. (1946). Giasg. med. J., 27, 313

Croskery, S. E. (1928). Brit. med. J., 1, 494.

Jacobs, A. (1960). J. clin. Path., 13, 463. (1961a). Brit. J. Cancer, 15, 736. (1961b). J. clin. Path., 14, 610.

Jones, A. M., and Owen, R. D. (1928). Brit. med. J., 1, 256

Jones, R. F. McN. (1961). J. Laryng., 75, 529.

Kelly, A. B. (1919). Ibid., 34, 285.

Kirchenberger, W., and Flett, R. L. (1946). Ibid., 61, 396

Lederman, M. (1956). Indian J. Radiol., Souvenir number.

McGibbon, J. (1935). J. Laryng., 50, 329.

Moersch, H. J., and Conner, H. M. (1926). Arch. Otolaryng., 4, 112 .

Owen, R. D. (1950). Proc. roy. Soc. Med., 43, 157

Paterson, D. R. (1919). J. Laryng.. 34, 289.

Simpson, R. R. (1939). Ibid., 54, 738 .

Trowell, H. C. (1960). Non-infective Disease in Africa. Arnold, London.

Waldenström, J., and Kjellberg, S. R. (1939). Acta radiol. (Stockh.), 20, 619.

Welin, S. (1953). Brit. J. Radiol., 26, 218

Weisberger, D. (1957). J. Amer. dent. Ass., 54, 507.

Wilkinson, J. F. (1950). Brit. med. J., 2, 576.

Witts, L. J. (1931). Guy's Hosp. Rep., 81, 193.

Wynder, E. L., and Fryer, J. H. (1958). Ann. intern. Med., 49, 1106 . 